\title{
Changing proximal femoral geometry in north east Scotland: an osteometric study
}

\author{
R A Duthie, M F Bruce, J D Hutchison
}

Department of Orthopaedics, University of Aberdeen Medical School, Aberdeen AB9 2ZD

R A Duthie, registrar J D Hutchison, professor

Department of Biomedical Sciences, Marischa College, Aberdeen AB10 1YS M F Bruce, lecturer

Correspondence to: Mr Duthie

BMJ 1998;316:1498

\section{Subjects, methods, and results}

The 120 dried femurs in the anatomy collection of the University of Aberdeen were obtained from a cross section of local people who had donated their bodies to the medical school since 1900 . The population of north east Scotland was stable over this period. Of the 71 from people who had died between 1900 and 1920, 28 were from women; of the 49 from people who died in the 1980s, 27 were from women. A standard osteometric board was used to measure femoral length; femoral head diameter, neck width, and neck length were measured with sliding calipers, and a commercially available goniometer was used to measure femoral neck anteversion.

Results were analysed using two way analysis of variance, taking sex and time period into account. Femoral dimensions and the percentage increase over time are given in the table. Measurements in men were greater than those in women for all dimensions $(\mathrm{P}<0.001)$. In both sexes, a small but significant increase in the femoral length and a greater increase in neck width and head diameter were seen. A more significant increase was seen in the length of the femoral

Mean (SE) femoral dimensions and percentage increase over time in men and women who died in 1900-20 and in the 1980s

\begin{tabular}{|c|c|c|c|c|}
\hline \multirow[b]{2}{*}{ Dimension } & \multicolumn{2}{|c|}{ Time of death } & \multirow[b]{2}{*}{ Increase (\%) } & \multirow[b]{2}{*}{$P$ value } \\
\hline & $1900-20$ & 1980s & & \\
\hline \multicolumn{5}{|c|}{ Femoral length $(\mathrm{mm})$ : } \\
\hline Men & $457.3(4.3)$ & $464.9(5.2)$ & $1.7(0.6)$ & 0.05 \\
\hline Women & $422.0(3.1)$ & $428.4(4.1)$ & $1.5(0.5)$ & 0.05 \\
\hline \multicolumn{5}{|c|}{ Neck length $(\mathrm{mm})$ : } \\
\hline Men & $34.9(0.6)$ & $38.3(0.8)$ & $9.7(1.0)$ & $<0.001$ \\
\hline Women & $32.5(0.9)$ & $35.0(0.7)$ & $8.7(0.9)$ & $<0.001$ \\
\hline \multicolumn{5}{|c|}{ Neck width $(\mathrm{mm})$ : } \\
\hline Men & $34.1(0.4)$ & $35.8(0.6)$ & $5.0(0.6)$ & $<0.05$ \\
\hline Women & $30.6(0.6)$ & $32.1(0.4)$ & $4.9(0.6)$ & $<0.05$ \\
\hline \multicolumn{5}{|c|}{ Head diameter $(\mathrm{mm})$ : } \\
\hline Men & $48.5(0.4)$ & $50.2(0.6)$ & $3.5(0.4)$ & $<0.05$ \\
\hline Women & $43.7(0.5)$ & $45.2(0.6)$ & $3.4(0.5)$ & $<0.05$ \\
\hline \multicolumn{5}{|c|}{ Anteversion (degrees): } \\
\hline Men & $7.9(0.8)$ & $4.4(1.3)$ & & NS \\
\hline Women & $7.5(1.2)$ & $7.4(1.0)$ & & NS \\
\hline
\end{tabular}

neck, but no significant change in neck anteversion was evident.

\section{Comment}

This osteometric study confirms the results of radiological studies. ${ }^{2}{ }^{3}$ The length of the femoral neck has increased, as have femoral length, neck width, and head diameter, but femoral neck anteversion has not changed significantly. The change in the geometry of the proximal femur seems to be similar in men and women and may result from improved childhood nutrition and general living standards.

These findings may be related to the increase in hip fractures. Patients who have trochanteric fractures are 3.7 years older and have greater bone loss than those with femoral neck fracture. ${ }^{5}$ Factors in addition to age and bone density may have a role in femoral neck fracture, and we suggest that the changing geometry of the proximal femur shown here may be important. This view is supported by other work showing that a maternal history of hip fracture increases the risk of femoral neck fracture 2.9 times relative to trochanteric fractures. In addition, bone mineral density in patients with cervical fractures was not significantly lower than that of controls matched for age.

The femoral neck seems to be becoming longer and thinner. A longer femoral neck is more likely to fracture for biomechanical reasons. An increase in hip axis length of $1 \mathrm{SD}$ doubles the risk of hip fracture. ${ }^{4}$ The most critical aspect of the hip axis is probably the femoral neck; any increase in this length could increase the risk of fracture.

Treatment to prevent osteoporosis increases the bone mineral density of the trochanteric region more than that of the neck of the femur and may therefore be more effective in preventing extracapsular fractures than intracapsular fractures. ${ }^{5}$ Proximal femoral geometry with increasing length of the femoral neck may be more important in the aetiology of intracapsular fractures. Current preventive measures are likely to have limited effect on the incidence of cervical fracture.

\footnotetext{
We thank Dr T Ringrose for his help with statistical analysis. Funding: None.

Conflict of interest: None.

1 Wallace WA. The increasing incidence of fractures of the proximal femur; an orthopaedic epidemic. Lancet 1983;i:1413-4.

2 Reid IR, Chin K, Evans MC, Jones JG. Relation between increase in length of hip axis in older women between 1950s and 1990s and increase in age specific rates of hip fractures. BMJ 1994;309:508-9.

3 O'Neill TW, Grazio S, Spector TD, Silman AJ. Geometric measurements of the proximal femur in UK women: secular increase between the late 1950s and early 1990s. Osteoporosis Int 1996;6:136-40.

4 Faulkner KG, Cummings SR, Black D, Palermo L, Gluer CC, Genant HK. Simple measurement of femoral geometry predicts hip fracture-the study of osteoporotic fractures. J Bone Mineral Res 1993;8:1211-7.

5 Vega E, Mautalen C, Gomez H, Garrido A, Melo L, Sahores AO. Bone mineral density in patients with cervical and trochanteric fractures of the proximal femur. Osteoporosis Int 1991;1:81-6.

(Accepted 31 October 1997)
} 